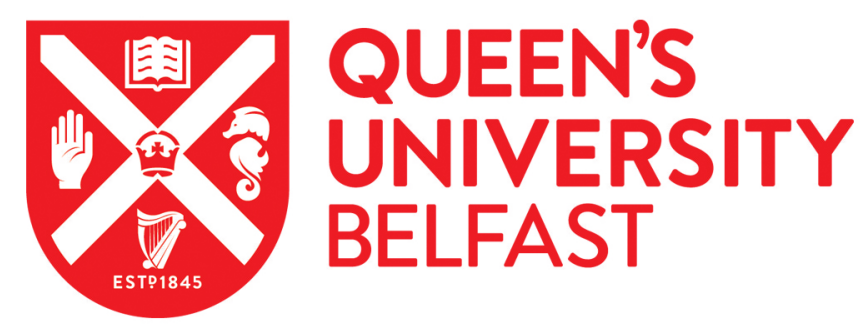

\title{
Variable Temperature Broadband Microwave and Millimeter Wave Characterization of Electrochromic (WO3/LiNbO3/NiO) Thin Films
}

Norooziarab, M., Bulja, S., Cahill, R., Kopf, R., Chen Hu, T. C., \& Tate, A. (2018). Variable Temperature Broadband Microwave and Millimeter Wave Characterization of Electrochromic (WO3/LiNbO3/NiO) Thin Films. IEEE Transactions on Microwave Theory and Techniques, 66(2), 1070-1080. https://doi.org/10.1109/TMTT.2017.2766624

Published in:

IEEE Transactions on Microwave Theory and Techniques

Document Version:

Peer reviewed version

Queen's University Belfast - Research Portal:

Link to publication record in Queen's University Belfast Research Portal

Publisher rights

(c) 2017 IEEE.

This work is made available online in accordance with the publisher's policies. Please refer to any applicable terms of use of the publisher.

\section{General rights}

Copyright for the publications made accessible via the Queen's University Belfast Research Portal is retained by the author(s) and / or other copyright owners and it is a condition of accessing these publications that users recognise and abide by the legal requirements associated with these rights.

Take down policy

The Research Portal is Queen's institutional repository that provides access to Queen's research output. Every effort has been made to ensure that content in the Research Portal does not infringe any person's rights, or applicable UK laws. If you discover content in the Research Portal that you believe breaches copyright or violates any law, please contact openaccess@qub.ac.uk. 


\title{
Variable Temperature Broadband Microwave and Millimeter Wave Characterization of Electrochromic $\left(\mathrm{WO}_{3} / \mathrm{LiNbO}_{3} / \mathrm{NiO}\right)$ Thin Films
}

\author{
Majid Norooziarab, Student Member, IEEE Senad Bulja, Senior Member, IEEE, Robert Cahill, Senior \\ Member, IEEE, Rose Kopf, T. C. Hu, and A. Tate
}

\begin{abstract}
This paper reports for the first time, the dielectric characterization of a new, electronically tuneable electrochromic (EC) thin film material over the frequency range $1 \mathrm{GHz}$ to 67 GHz, at temperatures of $7^{\circ} \mathrm{C}, 2^{\circ} \mathrm{C}$ and $50^{\circ} \mathrm{C}$. Test cells composed of a microstrip line terminated with coplanar waveguide (CPW) transitions were fabricated to facilitate on wafer RF measurements and the application of different bias voltages using a standard CPW probe station. A precise curve fitting technique based on full wave simulations was used to extract the permittivity and loss tangent values of the material. The validity of the dielectric extraction technique was first demonstrated by employing a known material, silicon dioxide $\left(\mathrm{SiO}_{2}\right)$. It is shown that the dielectric tunability of the EC material varies between $11.3 \%(1 \mathrm{GHz})$ and $7.5 \%(67 \mathrm{GHz})$ at $23^{\circ} \mathrm{C}$, and the measured loss tangent varies between 0.012 (OFF, $0 \mathrm{~V}$, state) and $0.025(\mathrm{ON}, 6 \mathrm{~V}$, state). Above room temperature the devices exhibit higher values of dynamic tunability and a small increase in insertion loss. The results obtained for this first generation of tuneable EC material are encouraging, and many of the dielectric properties are shown to compare favourably with other, more mature bulk tuneable media, such as liquid crystals.
\end{abstract}

Index Terms - electrochromic (EC) thin film material, temperature- controlled measurements, thin film microstrip lines (TFMLs), dielectric characterization, microwave phase shifters.

\section{INTRODUCTION}

$\mathrm{T}$ O ENHANCE the performance of many modern wireless communications networks, RF front-ends often require reconfigurable or multi-band circuits to satisfy the demanding operating system requirements. In this regard, the need for new microwave and millimetre wave phase shifting devices has led to ever increasing demands for a new generation of

Manuscript received April 14, 2017, revised September 1, 2017, and published Oct. 2017.

This work was supported by Nokia- Bell Labs and partly by Marie Curie European Industrial Doctorate (EID) programme ARTISAN (grant no. 316426).

M. Norooziarab and S. Bulja are with Nokia- Bell Labs, Blanchardstown Business and Technology Park, Snugborough Road, Blanchardstown, Dublin 15, Ireland (e-mail: majid.norooziarab@nokia.com).

R. Cahill is with the ECIT Institute, School of Electronics, Electrical Engineering and Computer Science, The Queen's University Belfast, Northern Ireland Science Park, Belfast BT3 9DT, Northern Ireland, UK.

R. Kopf, T. Hu and A. Tate are with Nokia Bell Labs, 600-700 Mountain Avenue, Murray Hill, New Jersey NJ07974, USA. materials which exhibit dielectric tunability, induced by the application of a quasi-static bias voltage. Towards this end, the salient electrical properties (relative permittivity, tunability and loss tangent) of several potentially suitable materials such as ferroelectrics (FE) and liquid crystals (LC) have recently been reported [1] - [7], and their use in practical applications such as phase shifters and electronic beam steering antennas has been demonstrated [8].

In 2016, two of the authors reported, for the first time, a new class of dielectric material, namely Electro-Chromic (EC) films, which were shown to exhibit electronic tunability in the frequency range from $1 \mathrm{GHz}$ to $20 \mathrm{GHz}$ [9]. The work was inspired by observations in the optical frequency [10], [11] where a change in colour occurs upon EC films actuation by application of a low DC bias voltage. Although the optical properties of EC have been widely reported in the literature, only two works [9], [12] have elaborated on the behaviour of these films in the microwave band, and, to the best of our knowledge, no study has ever been conducted to establish the electrical behaviour of EC at different operating temperatures and in the millimetre wave band.

In this paper, temperature-controlled measurements between $7^{\circ} \mathrm{C}$ and $50^{\circ} \mathrm{C}$ have been made in the $1 \mathrm{GHz}$ to 67 $\mathrm{GHz}$ frequency range of solid-state inorganic, thin EC films with a complimentary structure of $\mathrm{WO} 3 / \mathrm{LiNbO} 3 / \mathrm{NiO}$. The results are shown to compare favourability with LC mixtures, which give a satisfactory tunability and loss, but only over a limited temperature range where the material exists in the nematic phase state [6], [7]. Test cells previously developed and successfully employed for the work reported in [9], are also used in the present measurements in a temperaturecontrolled experimental set-up, suitable for wafer probing. Each test cell consists of two wideband coplanar waveguide (CPW) to microstrip line transitions to facilitate on-wafer RF measurements as well as to provide the required bias voltage excitation [13]. Initially, identical test cells constructed with a silicon dioxide $\left(\mathrm{SiO}_{2}\right)$ substrate are measured and characterized. Widespread knowledge of the dielectric characteristics of $\mathrm{SiO}_{2}$ [14], is used to confirm the validity of the experimental arrangement and the dielectric parameter extraction technique, which is subsequently used to obtain the dielectric permittivity and loss tangent values of the EC material for biased and unbiased states. 


\section{ElECTROCHROMIC (EC) MATERIALS}

EC dielectric materials are multi-layered composites deposited sequentially on a substrate as shown in Fig. 1 (a). The physical structure can be divided into four parts: (1) two conducting electrodes that permit the application of the bias voltage; (2) ion conductor or the electrolyte, which is the middle layer that acts as a tank of available ions and has a strong influence on the device performance; it must have a high ion conductivity (typically $\sigma_{\mathrm{i}}>10^{-7} \mathrm{~S} / \mathrm{cm}$ ) but low electron conductivity $\left(\sigma_{\mathrm{e}}<10^{-10} \mathrm{~S} / \mathrm{cm}\right)$; (3) EC layer at the cathode end where ions and electrons are inserted into or extracted from in order to change the associated colouration of the layer. The EC layer should be capable of conducting electrons as well as ions; (4) ion storage layer at the anode end is sometime present and, ideally, displays electrochromic properties complimentary to that of the cathodic EC film. In this case, the EC device contrast is improved since two chromic layers are bleached and coloured together (one cathodically by losing electrons and the other anodically by gaining electrons). Assuming a duality between optical (colour) characteristics and dielectric properties of the EC material, a higher contrast can be interpreted as increased dielectric tunability, however, this needs to be investigated using several EC structures.

Applying a DC bias voltage of the order of a few volts to the device causes the electrons (from the electrodes) and ions (from the electrolyte) to either flow in or out of the EC film(s), thus changing the optical absorption characteristics [15]. The device exhibits a long-term open circuit memory, i.e., the optical properties remain stable for long periods of time. A reverse DC voltage can be used to accelerate its return to the original optical properties.

Several distinct classes of materials have been extensively investigated for optical EC applications including organic and inorganic substances such as conducting polymers and transition metal oxides, respectively. Transition metal oxides must be employed in the form of thin films, typically less than $0.5 \mu \mathrm{m}[16]$. They have the advantage of a long lifetime and a high contrast (the colour changes from transparent to blue) [17]. On the other hand, conducting polymers can be made thicker and have a faster response time with abundant changing colours (multiple colours are observed for a variable DC bias voltage) [17]. Inorganic compounds are generally preferred electrolytes, due to their durability, long life, wide temperature ranges and ease of fabrication [10].

For the work presented in this paper, tungsten trioxide $\left(\mathrm{WO}_{3}\right)$ and Nickel oxide $(\mathrm{NiO})$ are employed with a thickness of $150 \mathrm{~nm}$ and $120 \mathrm{~nm}$, respectively, whereas $\mathrm{LiNbO}_{3}$ with a thickness of $730 \mathrm{~nm}$ is chosen as the electrolyte since it meets the conductivity requirements [10]. The high frequency modulation of this all solid-state inorganic thin film EC device with a complementary structure of $\mathrm{WO}_{3} / \mathrm{LiNbO}_{3} / \mathrm{NiO}$ is investigated at different temperatures using a novel test cell which is described in the next section.

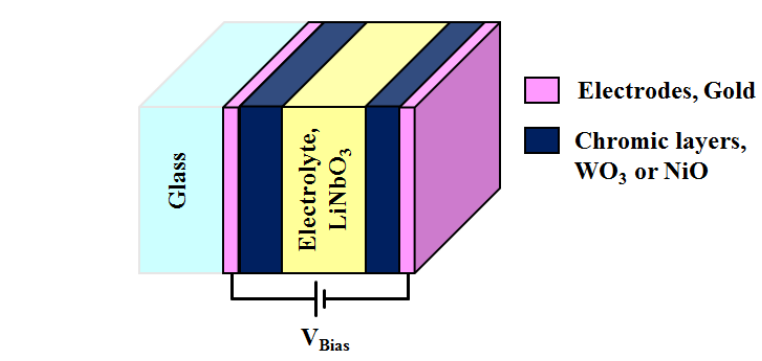

(a)

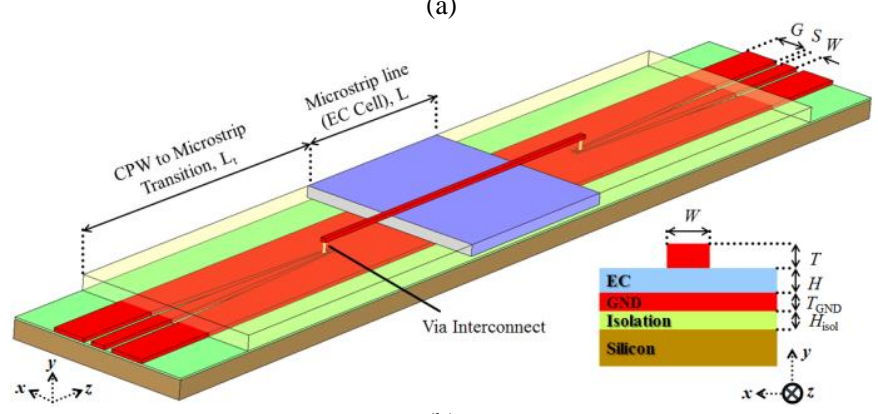

(b)

Fig. 1 (a) Topology of a conventional EC material; each layer of the device is deposited separately; (b) Topology of the EC test cell with the CPW transitions and the microstrip line section (not to scale). Also shown in the inset is the side view of the microstrip line section.

\section{MEASUREMENT SETUP}

A. Test Cells

In order to characterize the dielectric properties of the EC material over a wide frequency range, a new device architecture was developed consisting of two vertical transitions from a coplanar waveguide (CPW) to a microstrip line, Fig. 1 (b). The signal path of the CPW section is connected through a via to a microstrip line of length $\mathrm{L}$. The multilayer EC cell of Fig. 1 (a) is then employed as the dielectric material (shown in green) for the microstrip line whose ground plane and microstrip line are used to bias the EC cell. In addition to the unknown EC material whose dielectric properties are to be extracted, test cells based on $\mathrm{SiO}_{2}$ were also designed, fabricated and their dielectric characteristics extracted to demonstrate the validity of the measurements and material parameter extraction technique.

It should be pointed out that both test cells based on the multilayer EC dielectric material and the $\mathrm{SiO} 2$ have a similar thickness of about $1 \mu \mathrm{m}$. To ensure that the thicknesses of these two layers are the same, specific dimension measurements were performed during fabrication of the test cells [9]. As such, all of the individual layers in the test cells were characterized using Stylus profilometry on a KLA Tencore P-11 profilometer to determine the thickness. In addition, a Rudolph Auto ELII ellipseometer, and NanoSpec 6100 Interferometer were used to determine the refractive index and the thickness of the individual $\mathrm{WO} 3, \mathrm{NiO}$ and $\mathrm{LiNbO}_{3}$ layers prior to actual device fabrication. Further to this, measured dimensions of the cell thickness were obtained using Scanning Electron Microscopy (SEM) after fabrication.

It is observed from Fig. 1 (b) that two CPW- to- microstrip line transitions are employed in the test cell to permit the 


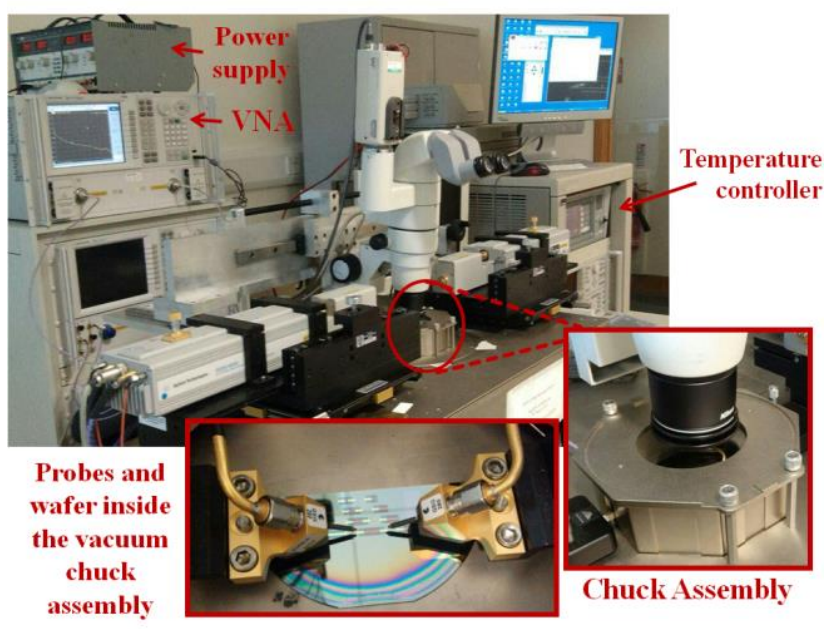

Fig. 2 Test Setup for the temperature- controlled measurements including the chuck assembly and the sample wafer inside. The wafer contains the test cells illustrated in Fig. 1.

measurement of the scattering (S) parameters using a standard CPW probe station. In addition, the probes provide the required DC bias voltage for EC material actuation.

Standard micro-fabrication techniques were used in the development of the EC cells. Each layer is sequentially deposited on an n-doped silicon wafer with a relative permittivity of $\varepsilon_{\mathrm{rSi}}=11.9$ and conductivity of $\sigma_{\mathrm{si}}=5 \mathrm{~S} / \mathrm{cm}$. To isolate the conductive silicon substrate from other layers of the composite structure and prevent wave propagation into the wafer, a $\mathrm{SiO}_{2}$ isolation layer with $H_{\text {isol }}=300 \mathrm{~nm}$ is next deposited by plasma-enhanced chemical vapour deposition (PECVD). Above this layer, a gold ground plane with $T_{\mathrm{GND}}=$ $520 \mathrm{~nm}$ is patterned with photoresist, deposited by e-beam evaporation, and lifted-off on the top surface of $\mathrm{SiO}_{2}$ to create the pattern of the CPW. In the design of the CPW, the permittivity value $\varepsilon_{\mathrm{r}}=3.78$ is assumed for the insulating thin $\mathrm{SiO}_{2}$ layer, and the geometric parameters $(G=180 \mu \mathrm{m}, S=44$ $\mu \mathrm{m}$ and $W=80 \mu \mathrm{m}$ ) were optimised using CST Microwave Studio to give a $50 \Omega$ characteristic impedance. The overall length of the transition is $L_{\mathrm{t}}=2200 \mu \mathrm{m}$. The EC material, bound by two $\mathrm{SiO}_{2}$ barrier layers (shown in green in Fig. 1 (b)), is then patterned, e-beam deposited and lifted-off on the surface of the ground plane with a thickness of $H \approx 1 \mu \mathrm{m}$. Next, the barrier layers are etched away to open vias of diameter $d_{\text {via }}=3 \mu \mathrm{m}$. The gold microstrip line of width $W \approx 4$ $\mu \mathrm{m}$ and thickness $T=2.58 \mu \mathrm{m}$ is patterned, e-beam deposited and lifted-off. This line connects the signal path of the CPW through the vias. In this case, the characteristic impedance of the microstrip line section based on the known $\mathrm{SiO}_{2}$ dielectric material is equal to $50 \Omega$ and is matched to the impedance of the two ports.

\section{B. Thermal Control}

An E8361C (10 MHz-67 GHz), Agilent vector network analyzer (Keysight Technologies), is used for S-parameter measurements of the EC test structures, whereas for the temperature-controlled measurements, a Thermochuck TP03200 system suitable for wafer probing is used, Fig. 2. The TP03200 system consists of a controller, a stand-alone

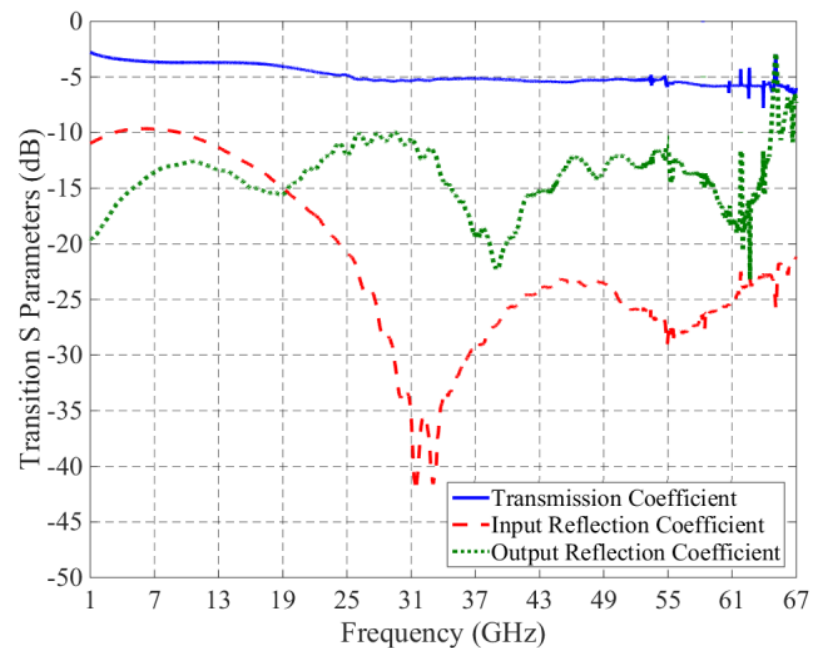

Fig. 3 Extracted S-parameters of the CPW-to-microstrip using measured data

cooler and a temperature controlled vacuum chuck assembly which hosts the fabricated wafers. The chuck is a high precision thermal platform and is electrically isolated from the wafer substrate. The system enables thermal measurements from $-65^{\circ} \mathrm{C}$ to $300^{\circ} \mathrm{C}$ with $\pm 0.5^{\circ} \mathrm{C}$ accuracy, however, a smaller range of $7^{\circ} \mathrm{C}$ to $50^{\circ} \mathrm{C}$ was chosen for this measurement campaign.

\section{DIELECTRIC PARAMETER EXTRACTION}

In order to extract the unknown dielectric parameters of the microstrip line section depicted in Fig. 1 (b), the contribution of the CPW to microstrip transitions must first be dembedded from the test cell measurements. This is done using the following matrix expression,

$\left[T_{\text {meas }}\right]=\left[T_{\text {trans }}\right] \cdot\left[T_{\text {Line }}\right] \cdot\left[T_{\text {rev-trans }}\right]$

where $\left[T_{\text {meas }}\right]$ represents the overall measured transmission matrix of the CPW/microstrip/CPW test structure, Fig. 1(b), obtained from the measured $\mathrm{S}$ parameters. Similarly $\left[T_{\text {trans }}\right]$ and $\left[T_{\text {rev_trans }}\right]$ are the transmission matrices of the transitions for the forward and reverse direction, respectively. Finally $\left[T_{\text {Line }}\right]$ represent the transmission matrix of the microstrip line section whose dielectric material is unknown, and is to be extracted.

The method discussed in [13], which is effectively a twotier thru-line (TL) technique, can be used to extract the $\mathrm{S}$ parameters of the CPW-to-microstrip line transitions (Appendix I). Here, the Thru standard refers to a structure with only two transitions connected back-to-back $(L=0)$ while the Line standard represents two back-to-back transitions connected through a length of a line, $L$. It should be pointed out that the microstrip line section in the line standard, which has a length of $L=2 \mathrm{~mm}$ in this study, should be exposed to $\mathrm{SiO}_{2}$ to avoid reflections. In this case, the $\mathrm{S}$ parameters of the transitions are obtained following the procedure provided in [13] and are shown in Fig. 3. As can be seen from this figure, the measured input reflection coefficient (at the CPW input port) is quite different from the output 
reflection coefficient (observed from the microstrip side). This is due to the geometric asymmetry of the transition which presents a CPW configuration at one end and a microstrip line topology at the other end. In both cases the reflection coefficients are below $-9.6 \mathrm{~dB}$ over the indicated frequency measurement range, $1 \mathrm{GHz}$ to $65 \mathrm{GHz}$. The high loss evident in the measured transmission coefficients of the transitions is attributed to the thin dielectric and conducting layers. The extraordinary frequency behavior of thin film microstrip lines (TFMLs) compared to conventional microstrip lines is thoroughly discussed in [18].

Once the $\mathrm{S}$ parameters of the transitions are obtained, the transmission matrix of the microstrip line section, $\left[T_{\text {Line }}\right]$, can be achieved from (1). This matrix contains information of the unknown complex propagation constant of the EC cell, $\gamma=\alpha$ $+j \beta$, however, it also contains the effect of the impedance transition from the microstrip line deposited on the $\mathrm{SiO}_{2}$ layer to the unknown dielectric characteristic of the EC material, Fig. 1 (b). In order to extract the dielectric characteristics of the unknown dielectric material accurately, the effect of this transition needs to be taken into account [9]. Due to the symmetry and reciprocity properties of the microstrip line the following holds,

$$
\begin{aligned}
& T_{11} \text { Line } T_{22} \text { Line }-T_{21} \text { Line } T_{12} \text { Line } \\
& T_{21} \text { Line } \\
& =-T_{12} \text { Line }
\end{aligned}
$$

Where $T_{11 \text { Line }}, T_{12 L i n e}, T_{21 L i n e}$ and $T_{22 L i n e}$ are the matrix elements of $\left[T_{\text {Line }}\right]$. Regardless of the matching conditions at the terminals of the microstrip line, the following expression for the unknown complex propagation constant, $\gamma$, can be obtained [9], [19] using the measured transmission matrix, $\left[\mathrm{T}_{\text {Line }}\right]$,

$$
\gamma=\frac{1}{L} \cosh ^{-1}\left(\frac{1+T_{11}^{2} \text { Line }-T_{21}^{2} \text { Line }}{2 T_{11} \text { Line }}\right)
$$

It should be noted that (3) is the general formula for the complex propagation constant of a symmetrical transmission line with length $\mathrm{L}$ supporting a single mode propagation [20]. In particular, (3) represents the extracted complex propagation constant of the EC cell when the effect of the transition from the $\mathrm{SiO}_{2}$ layer to the unknown dielectric characteristic of the $\mathrm{EC}$ material is taken into account. Effectively, in this way, the microstrip line exposed to the EC material becomes reflectionless and can be uniquely characterized by the propagation constant, $\gamma$, and by the knowledge of the dimensions and metal conductivities obtained from scanning electron microscopy (SEM) measurements and DC resistance measurements, respectively. Furthermore, it should be noted that the calculation of the cosh function in Eq. (3) involves the squareroot and complex natural logarithm functions which require further unwrapping of the imaginary part as well as the correction of the sign of the real part [3], [13] in order to properly obtain $\beta$ and $\alpha$, respectively.

The effective parameters of the EC-based thin film microstrip line (TFML) in Fig. 1 (b) can be obtained using the measured complex propagation constant; $\varepsilon_{\text {eff }}=\left(\gamma / \gamma_{0}\right)^{2}$ [20]. Here, $\gamma_{0}=\omega / c$ is the free space wave number and $\gamma$ can be obtained from (3). The effective permittivity is interpreted as the permittivity of a homogeneous medium that equivalently replaces the air, conducting layers and the dielectric material [20]. In the case of a TFML structure, the effective permittivity is heavily influenced by the properties of the conductors as a consequence of wave propagation in thin dielectric and conducting layers. More specifically, the thin dielectric layer results in densely distributed electromagnetic (EM) fields which can propagate inside the thin conductors (or even radiate into the air) at sufficiently low frequencies where the conductor thickness is less than one skin depth [18].

This behaviour observed for TFML structures makes the extraction of the relative parameters of the EC material from the effective parameters of the TFML highly complicated, as described in [21] - [23]. For this purpose, the authors developed an analytical method and a curve-fitting optimization procedure [18], based on the full-wave simulation software CST. The techniques were initially evaluated using thin $\mathrm{SiO}_{2}$ as the dielectric material and it was shown that the extracted relative permittivity based on the fullwave simulation procedure shows an increased value and differs by $25 \%$ of the bulk $\mathrm{SiO}_{2}$ as reported in the literature [14]. However, such permittivity enhancement of thin film $\mathrm{SiO}_{2}$ is possibly due to impurities introduced into the thin grown layers during the fabrication process [18]. In particular, the $25 \%$ difference is in line with the results in [24] which report a permittivity enhancement of up to $26 \%$ for thin $\mathrm{SiO}_{2}$. The extracted loss tangent of thin $\mathrm{SiO}_{2}$ was about $\tan \delta \approx 4 \times$ $10^{-3}$ which is in line with the published results of [24]. The standard curve-fitting procedure in conjunction with full-wave simulations is used for accurate dielectric characterization of the EC material in [9], which tends to be time consuming due to the complex propagation nature in thin film conductors. In this regard, the analytical method proposed by the authors in [18] was used as a starting point in the optimization procedure to yield a time efficient and accurate dielectric characterization based on the designed TFML test structure.

To simulate the TFML structure in CST, the conductors are modelled as arbitrary materials with a relative permittivity obtained from the conductivity of the metal. Such a setting is essential since the CST solver models conductive strips as surface impedances, which avoids volume wave propagation in their interior. To obtain precise values of the high frequency dielectric characteristics of the unknown EC material, the conductivity of the conductive layers is obtained from DC resistance measurements, while the exact dimensions of the TFML are obtained using scanning electron microscopy (SEM) measurements. These measurements are later used in the curve fitting optimization in CST to match the simulated and measured complex propagation constants, $\gamma$, from which the unknown high frequency dielectric characteristics are obtained. The SEM measurements of the fabricated test cells show that the surface roughness is low enough to be neglected in the CST simulations. 
In addition, the optimization space in CST over which the desired dielectric characteristics are sought is defined by the width of the microstrip of $W=4 \pm 0.05 \mu \mathrm{m}$, conductor thickness for the microstrip line and the ground plane $T=2.58$ $\pm 0.05 \mu \mathrm{m}$ and $T_{\mathrm{GND}}=0.52 \pm 0.02 \mu \mathrm{m}$, and dielectric thickness $H=1 \pm 0.05 \mu \mathrm{m}$. Similarly, conductivities of the top and bottom gold layers derived from measurements of DC resistance and conductor geometries, considered in the range $(2.46 \pm 0.15) \times 10^{7} \mathrm{~S} / \mathrm{m}$ and $(3.64 \pm 0.15) \times 10^{7} \mathrm{~S} / \mathrm{m}$, respectively were also used as part of the optimization space in CST. In order to obtain the DC resistance measurements, we have used two needle probes connected to the signal line of the CPW at the input and output ports, Fig. 1 (b). The other end of the probes is connected to an LCR meter (Rhode \& Schwarz HM 8118). By performing these measurements for two test cells with different lengths of the microstrip line section and subtracting the measured resistances, the conductivity of the microstrip line can be calculated [22]. A similar approach is repeated to obtain the conductivity of the ground plane.

\section{RESULTS}

Based on the optimization technique using full wave CST simulator, described in the previous section, the proposed EC material composition of Fig. $1 \quad\left(\mathrm{WO}_{3} / \mathrm{LiNbO} / \mathrm{NiO}\right)$ is characterized between $1 \mathrm{GHz}$ to $67 \mathrm{GHz}$ for two different cases; (i) at room temperature (about $23^{\circ} \mathrm{C}$ ), unbiased and with DC bias voltage applied in steps of $1 \mathrm{~V}$ up to $6 \mathrm{~V}$, and (ii) at 0 $\mathrm{V}$ and $6 \mathrm{~V}$ for temperatures of $7^{\circ} \mathrm{C}, 23^{\circ} \mathrm{C}$ and $50^{\circ} \mathrm{C}$. A bias voltage of $6 \mathrm{~V}$ is adopted for the 'ON state' of the material in line with previous publications [9]. However, a brief discussion on the saturation limit of the EC material is provided in Section VI.

The length of the microstrip line exposed to the EC material is important in the dielectric extraction of the tunable material. Considering the frequency range of interest, a test-cell of length $L=2 \mathrm{~mm}\left(\lambda_{\mathrm{g}}\right.$ at $f=20 \mathrm{GHz}$ [9] $)$ was chosen in preference to the other devices that were constructed $(L=1$ $\mathrm{mm}, 3 \mathrm{~mm}$ and $5 \mathrm{~mm}$ ) to reduce the required simulation time in CST. Nevertheless, consistency of the extracted dielectric properties was verified by comparison with the results obtained from the other three structures.

For the scattering parameter measurements, a probe-station and a vector network analyser, calibrated using a standard short-open-load-thru (SOLT) method was used. The reference planes are at probe positions located at the ends of the CPW terminals on the device under test.

\section{A. Variable Bias Voltages at Room Temperature}

The complex dielectric permittivity of the EC material was extracted at room temperature for bias voltages from $0 \mathrm{~V}$ (OFF state) to $6 \mathrm{~V}$ ('ON' state) in $1 \mathrm{~V}$ steps. Here, the simulated and measured complex propagation constants, $\gamma$, of the EC based microstrip line were matched for all bias voltages. The propagation and attenuation constants corresponding to a thin film microstrip line of a length of 2 $\mathrm{mm}$ are obtained by matching the measured propagation

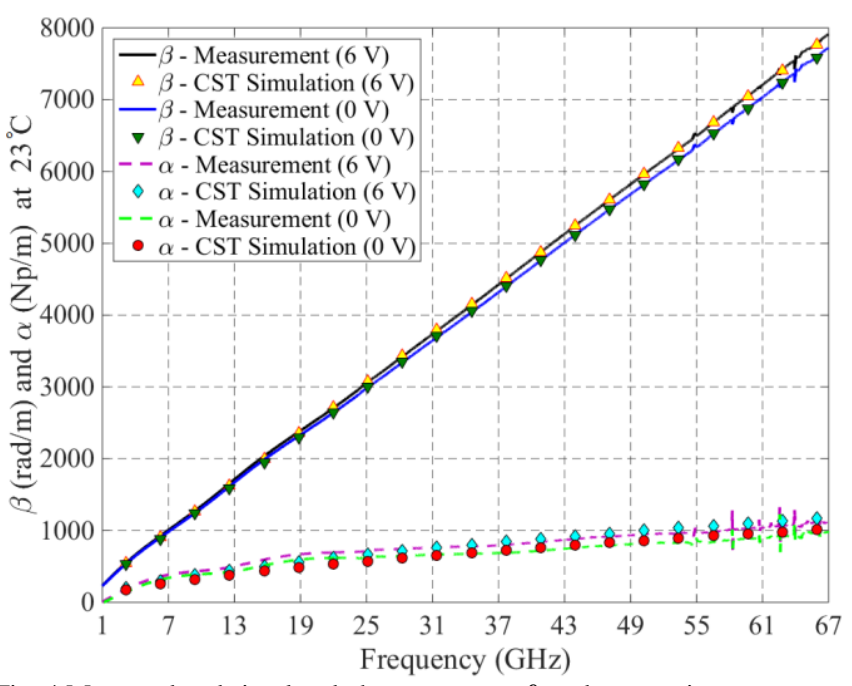

Fig. 4 Measured and simulated phase constant, $\beta$, and attenuation constant, $\alpha$, of the EC based TFML for two bias voltages of $0 \mathrm{~V}$ and $6 \mathrm{~V}$ at room temperature $\left(23^{\circ} \mathrm{C}\right)$.

constant to the one obtained by the CST optimisation procedure. Figure 4 shows the corresponding curves for the $\mathrm{OFF}$ and $\mathrm{ON}$ states of the EC material at $0 \mathrm{~V}$ and $6 \mathrm{~V}$, respectively, while the rest of the voltage steps are not shown for the sake of clarity. As evident, the measured and simulated propagation constants, $\beta$, are well matched. The largest error is related to the simulated attenuation constant, $\alpha$, and is about $10 \%$ over the indicated frequency range. It is believed that the differences observed are related to increased sensitivity to noise at higher frequencies.

The simulated curves for the attenuation and propagation constants show a greater error at low frequencies compared to high frequencies. This is understandable since at low frequencies the conductors are electrically thinner compared to their corresponding electrical thickness at higher frequencies. The effect of thinner conductors at low frequencies manifests itself in an increased sensitivity to the exact value of the conductor properties (thickness and conductivity). Further, since the conductor thickness is not perfectly uniform along the length of the thin microstrip line, the small undulations along its surface act as a source of error, which is, again, mostly perceivable at low frequencies. At higher frequencies, the effect of small undulations is less pronounced since the conductor in this case is electrically thicker. Another source of uncertainty lies with measurement uncertainty, which demonstrates itself as a noisy response, mostly evident above $f$ $=65 \mathrm{GHz}$, Fig. 4 .

Figure 5 (a) depicts the extracted dielectric constants of the EC material for all bias voltages. The results show that a threshold DC bias voltage of about $1 \mathrm{~V}$ is required to produce a measurable change in the permittivity of the EC delay line. The loss tangent is also extracted and shown in Fig. 5 (b). A comparison of the extracted dielectric properties illustrated in Fig. 5 with the only published results at room temperature in the frequency range of $1 \mathrm{GHz}$ to $20 \mathrm{GHz}$ [9], reveals that the relative permittivity and loss tangent of the EC are generally in good agreement; the maximum difference for the extracted relative permittivity is below $1 \%$ while it reaches $4 \%$ for the 


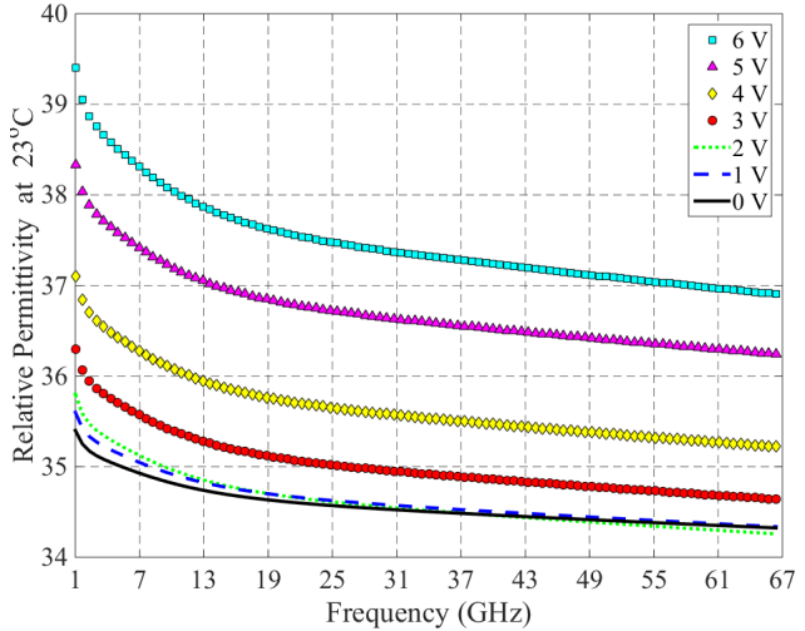

(a)

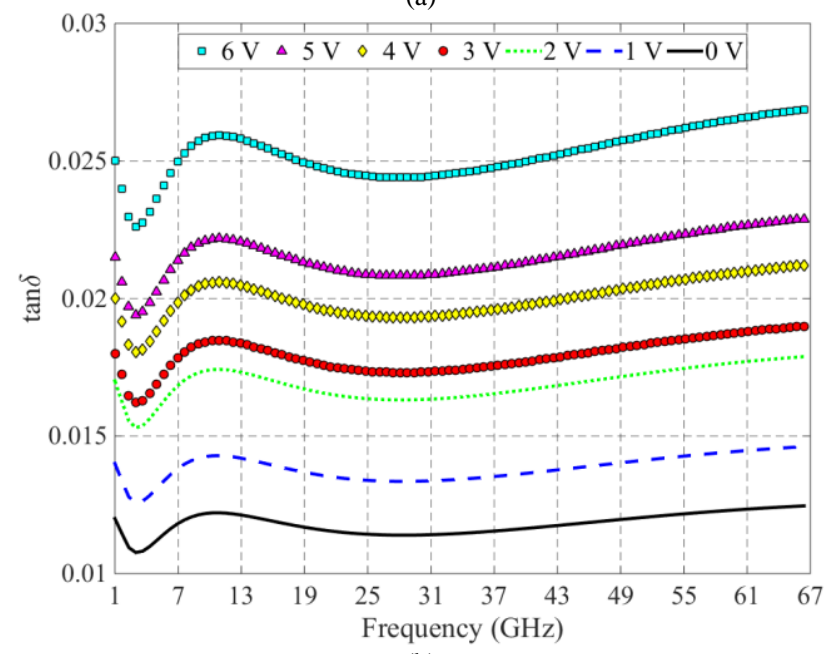

(b)

Fig. 5 Extracted dielectric parameters of the EC material at room temperature for a different DC voltages; (a) Relative permittivity versus frequency, (b) Extracted loss tangent, tan $\delta$.

extracted loss tangent. A temperature variation of the EC materials has not been publicly disclosed anywhere else and, as such, we cannot provide such a comparison. However, it would be possible to, as an example of our future work, compare the present, dielectric parameters obtained using a broadband method with an inherently more accurate single frequency cavity method. This can be the topic of a future research study to accurately characterize the tuneable EC material. Between $20 \mathrm{GHz}-67 \mathrm{GHz}$ the absolute values of the extracted permittivity decrease linearly and the tunability $(\Delta \varepsilon$ $\left.(f)=\varepsilon_{\mathrm{r}}(6 \mathrm{~V})-\varepsilon_{\mathrm{r}}(0 \mathrm{~V})\right)$ of the EC material varies between $11.3 \%$ at $1 \mathrm{GHz}$ and $7.5 \%$ at $67 \mathrm{GHz}$. The results show a weak variation of loss tangent with frequency for a given bias voltage. The maximum measured $\tan \delta=0.026$ at $67 \mathrm{GHz}$ for a bias voltage of $6 \mathrm{~V}$, is approximately twice the value obtained for the unbiased state. It is interesting to note that we observed that the EC material exhibits a memory effect and preserves its electrical properties for several hours after the bias voltage is removed. Furthermore, the tuning behaviour of the material is repeatable and the 'ON' to 'OFF' cycle dielectric parameters can be regained simply by reversing the $\mathrm{DC}$ bias voltage.

The performance of the EC device is predominantly dictated by the performance of its constituent layers; i.e., the EC film, the electrolyte and the ion storage layers. For the current EC test cells based on the combination of $\mathrm{WO}_{3} / \mathrm{LiNbO}_{3} / \mathrm{NiO}$, a switching time of 3 minutes is required for the full bias of the material. However, faster switching times can be achieved depending on the material composition, preparation condition and deposition method. For example, in [10], a switching time of less than 2 seconds is reported for the bleaching/colouration of an EC structure similar to the one considered here but with different layer thicknesses and deposition technique. This structure is considered for display technology applications. The reported durability (ON to OFF cycles) of the device is more than 2000 cycles and it exhibits a strong memory effect of about 24 hours. A comparative discussion on the switching dynamics of several EC structures can be found in [11], however, these results pertain to the characteristics observed at optical frequencies. The equivalent behaviour characterisation at micro-and $\mathrm{mm}$-wave frequencies has not yet been conducted.

It is useful to compare the extracted dielectric permittivity and loss tangent of the EC material with other available electronically tunable technologies such as liquid crystals (LCs) [3] - [7], ferroelectrics [1], [2] and CMOS based phase shifters [25], [26]. Among all these, the EC material can be best compared with LCs as they are both bulk-tuneable dielectric materials which can be continuously controlled by a low DC bias voltage (typically around $10 \mathrm{~V}$ ). In contrast, ferroelectrics require high bias voltages although they can achieve very large tuning ratios up to $200 \%$ [2]. Similarly, CMOS-based phase shifters can be implemented in a small area with discrete [25] or continuous [26] phase shifts. In both cases large phase shifts are achieved over a limited frequency range, since varactors are made to resonate by either serial or parallel connection with an inductor. This is unlike LCs or the proposed EC material which are bulk-tunable dielectric materials and provide a wide frequency and continuous control.

The first generation of LCs (K15) exhibits 10.5\% permittivity tunability [14] which is similar to the EC material reported in the present work. However, the dielectric tunability of the EC material is lower than that of the more sophisticated LC mixture (GT3-23001), about 27\%, which is commercially available from Merck $\mathrm{KGaA}$ and specially engineered for microwave applications [19]. On the other hand, the absolute value of the extracted relative permittivity of the present EC cells is approximately an order of magnitude higher than that reported for LCs [3] - [5]. In this case, the proposed EC composition may be suitable for those applications that cannot be practical with LCs; e.g. tunable varactors with high capacitance values and miniaturized phase shifters.

Although the extracted loss tangents obtained in this study are very similar to GT3-23001 [27], the loss tangent values are lower than most other experimental LCs specimens reported in the literature which lie in the range $\tan \delta \perp=0.05$ to 0.075 for the perpendicular state (OFF state) and $\tan \delta \|=0.03$ to 0.05 for the parallel state (ON state) at $30 \mathrm{GHz}[3]-[6]$. 


\section{B. Variable Temperature}

To investigate the temperature dependency of the dielectric properties of the EC material, the test setup already described in Fig. 2 is exploited. In this regard, measurements were made between $1 \mathrm{GHz}$ to $67 \mathrm{GHz}$ for two extreme bias states, $0 \mathrm{~V}$ and $6 \mathrm{~V}$, with the temperature of the experimental setup configured to both increase (decrease) to $50^{\circ} \mathrm{C}\left(7^{\circ} \mathrm{C}\right)$ from room temperature with the wafer containing the device under test inserted in the chuck assembly. This is done so that the electrical behaviour of the EC material is investigated for rising and falling temperatures. This contrasts with the characterisation of LC mixtures, where the temperature gradient during the measurement stage needs to be always positive. This is due to LC mixtures exhibiting supercritical behaviour, which manifests itself as a temperature hysteresis when cooled down [6] - [7].

The curve fitting optimization in CST is also applied for these two temperature points $\left(50^{\circ} \mathrm{C}\right.$ and $\left.7^{\circ} \mathrm{C}\right)$ to match the simulated and measured complex propagation constants, $\gamma$, Fig. 6 (a) and (b), respectively. The extracted dielectric

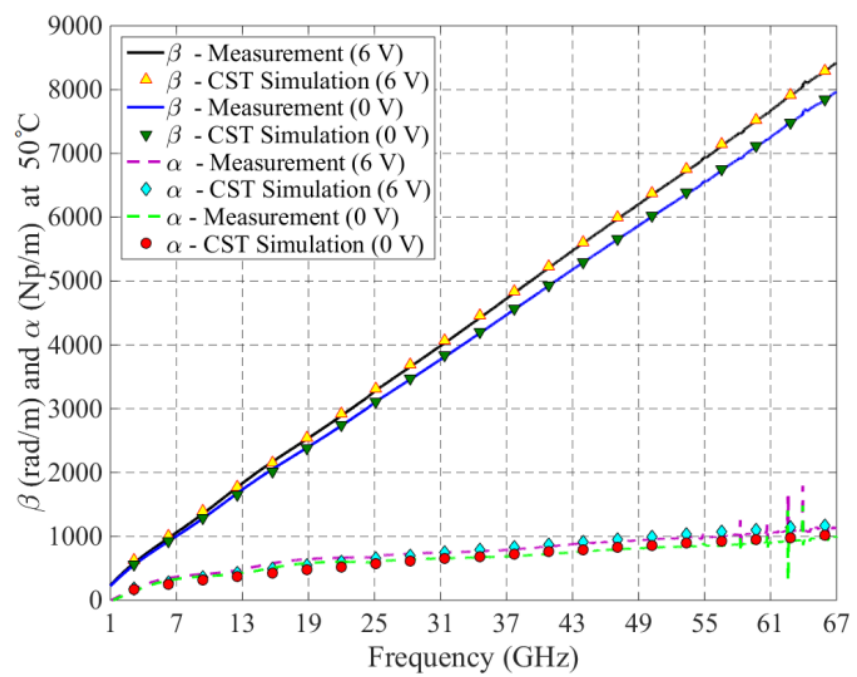

(a)

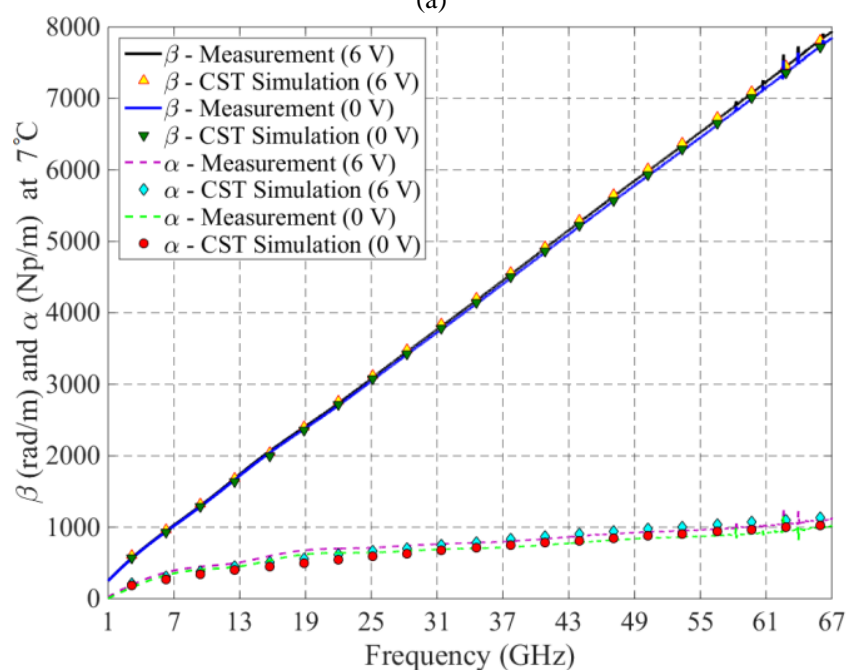

(b)

Fig. 6 Measured and simulated phase constant, $\beta$, and attenuation constant, $\alpha$, of the EC based TFML for two bias voltages of $0 \mathrm{~V}$ and $6 \mathrm{~V}$ at (a) $50^{\circ} \mathrm{C}$ and (b) $7^{\circ} \mathrm{C}$. parameters of the EC material at three different temperatures, $7^{\circ} \mathrm{C}, 23^{\circ} \mathrm{C}$ and $50^{\circ} \mathrm{C}$, are plotted in Fig. 7. As can be seen, the extracted relative permittivity, $\varepsilon_{\mathrm{r}}$, and loss tangent, $\tan \delta$, are both temperature sensitive, especially for the $\mathrm{ON}$ state $\left(\mathrm{V}_{\text {bias }}=\right.$ $6 \mathrm{~V})$.

Compared with the results at room temperature, a significant increase in the absolute permittivity is obtained at $50^{\circ} \mathrm{C}$ which produces an increase in the dielectric tunability, ranging from $16.4 \%$ at $1 \mathrm{GHz}$ to $12 \%$ at $67 \mathrm{GHz}$. Conversely the measurements at $7^{\circ} \mathrm{C}$ show that the EC material exhibits a smaller tunable range than at room temperature. For the unbiased device the variation in the permittivity with temperature follows the same trend, but the variation is significantly lower. Similarly, the variation of the loss tangent at different temperatures follows the same trend and it lies in the range $\tan \delta=0.012-0.017$ which is within the experimental accuracy of the measurement system. Interestingly for the biased ' $\mathrm{ON}$ ' state, $\tan \delta$ for $7^{\circ} \mathrm{C}$ and $50^{\circ} \mathrm{C}$ are both larger than the measured data obtained at room temperature $\left(23^{\circ} \mathrm{C}\right)$.

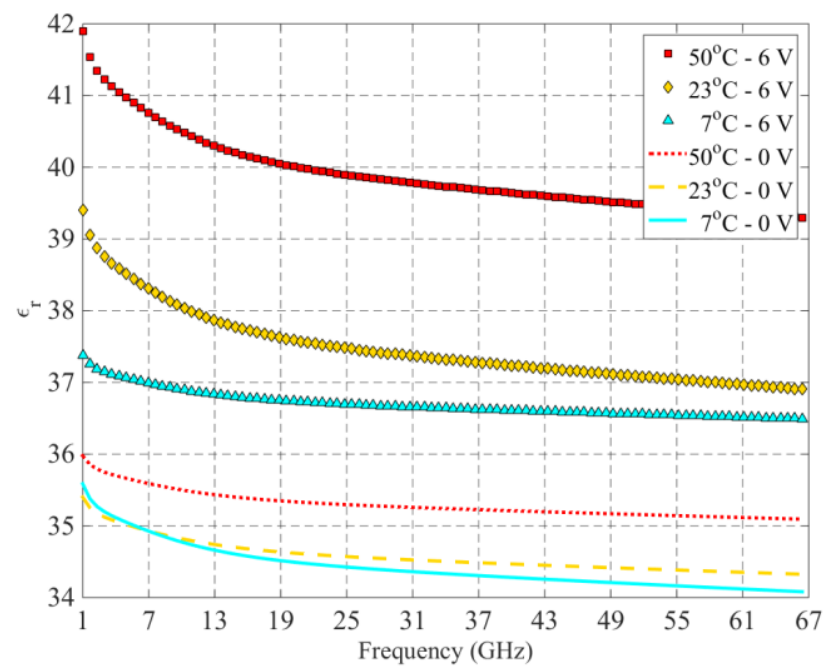

(a)

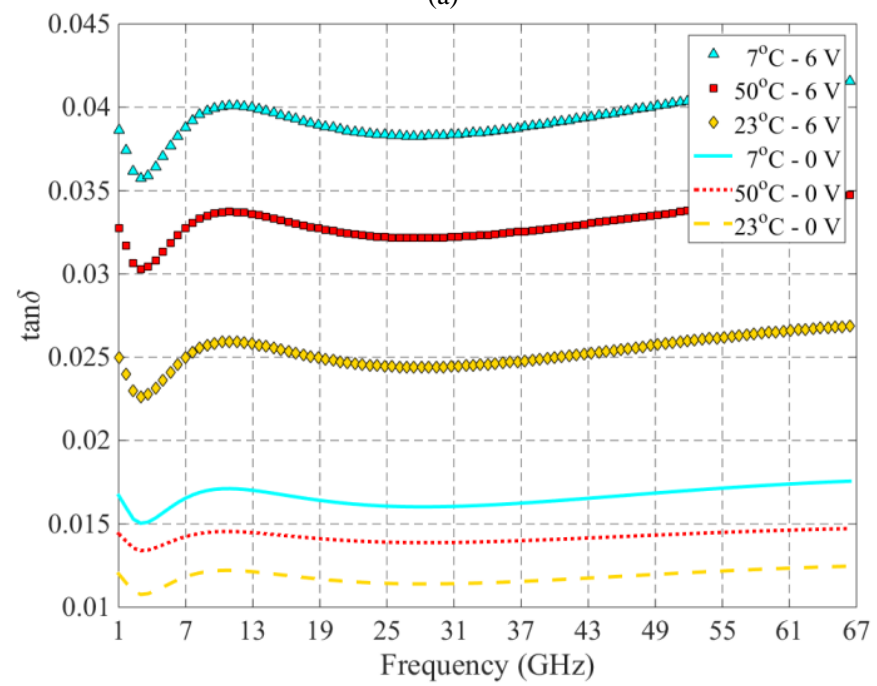

(b)

Fig. 7 Extracted parameters of the EC material at three temperatures of $7^{\circ} \mathrm{C}$, $23^{\circ} \mathrm{C}$ and $50^{\circ} \mathrm{C}$ for the 'OFF' state $(0 \mathrm{~V})$ and the 'ON' state $(6 \mathrm{~V})$; (a) Relative permittivity, $\varepsilon_{\mathrm{r}}$, and (b) Corresponding loss tangent, $\tan \delta$. 
TABLE I

COMPARISON OF MATERIAL PROPERTIES AT $20 \mathrm{GH}_{z}$

\begin{tabular}{c|c|c|c|c|c}
\hline \hline & Temp. & K15 & MDA-03-2838 & Temp. & Proposed EC \\
\hline \multirow{2}{*}{$\varepsilon_{\mathrm{r}}$} & $0^{\circ} \mathrm{C}$ & 2.58 & 2.75 & $7^{\circ} \mathrm{C}$ & 34.5 \\
(Unbiased) & $26^{\circ} \mathrm{C}$ & 2.57 & 2.72 & $23^{\circ} \mathrm{C}$ & 34.62 \\
& $80^{\circ} \mathrm{C}$ & 2.52 & 2.61 & $50^{\circ} \mathrm{C}$ & 35.34 \\
\hline \multirow{3}{*}{$\Delta$} & $0^{\circ} \mathrm{C}$ & 0.00 & 0.2 & $7^{\circ} \mathrm{C}$ & 2.24 \\
& $26^{\circ} \mathrm{C}$ & 0.018 & 0.63 & $23^{\circ} \mathrm{C}$ & 2.98 \\
& $80^{\circ} \mathrm{C}$ & 0.00 & 0.45 & $50^{\circ} \mathrm{C}$ & 4.68 \\
\hline \multirow{2}{*}{$\tan \delta$} & $0^{\circ} \mathrm{C}$ & 0.005 & 0.01 & $7^{\circ} \mathrm{C}$ & 0.016 \\
$($ Unbiased) & $26^{\circ} \mathrm{C}$ & 0.02 & 0.01 & $23^{\circ} \mathrm{C}$ & 0.011 \\
& $80^{\circ} \mathrm{C}$ & 0.075 & 0.02 & $50^{\circ} \mathrm{C}$ & 0.014 \\
\hline \multirow{2}{*}{$\tan \delta$} & $0^{\circ} \mathrm{C}$ & 0.005 & 0.01 & $7^{\circ} \mathrm{C}$ & 0.039 \\
(Biased) & $26^{\circ} \mathrm{C}$ & 0.03 & 0.02 & $23^{\circ} \mathrm{C}$ & 0.025 \\
& $80^{\circ} \mathrm{C}$ & 0.075 & 0.038 & $50^{\circ} \mathrm{C}$ & 0.032 \\
\hline \hline
\end{tabular}

TABLE II

MEASURed Phase ShIFT PER UNIT LENGTH AND

FOM OF LC AND EC-BASED PHASE SHIFTERS

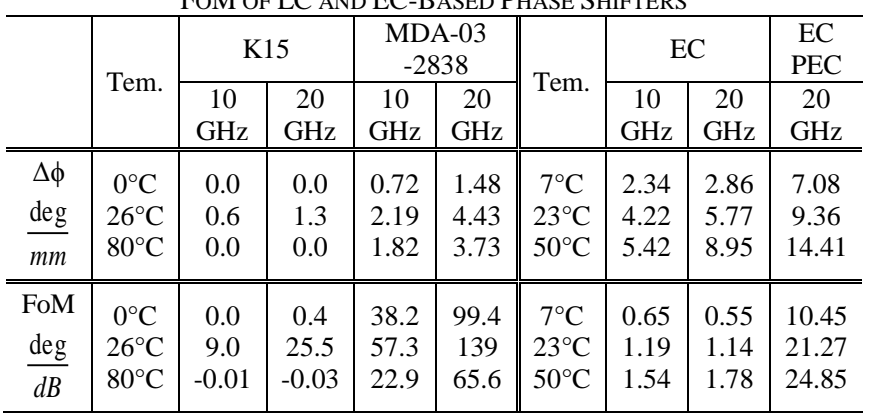

The extracted results in Fig. 7 can be also compared with LC mixtures. Table I compares temperature variations of the dielectric characteristics of the proposed EC material with those of two famous LCs; i.e., K15 and MDA-03-2838 [6]. In this case, the EC material has a wider operating temperature range compared to an LC mixture, $\mathrm{K} 15$, which has a usable temperature range between $20^{\circ} \mathrm{C}$ to $34.9^{\circ} \mathrm{C}$. The temperature range of an LC mixture, MDA-03-2838, also discussed in [6], is increased especially towards higher temperatures - a phenomenon which can be also observed in Fig. 7 for the proposed EC material. Nevertheless, the maximum dielectric tunability occurs for $50^{\circ} \mathrm{C}$ which is the highest adjustable temperature and, in this case, it would be pertinent to investigate the EC material behaviour in an even broader temperature range.

The dielectric tunability exhibited by the EC material can be exploited to realize electronically tuneable microwave and $\mathrm{mm}$-wave devices such as phase shifters, tuneable filters and phase agile antennas, to name but a few. Using a tuneable EC material for a phase-shifter device, the phase shift per unit length $(\Delta \varphi)$ and the Figure-of-Merit (FoM), defined as the ratio $\Delta \varphi /($ maximum insertion loss) can be calculated. It is assumed that the phase shifter takes form of a microstrip line, the same as the one used in the measurements of the EC properties (Fig. 1 (b)). In this regard, the frequency response of the microstrip line exposed to the EC material with $2 \mathrm{~mm}$ length is shown in Fig. 8 (a) and (b) at all three temperatures. The origin of the undulations observed at higher frequencies, particularly above $65 \mathrm{GHz}$, are two-fold; first, the CPW to microstrip line transitions are designed for a wideband

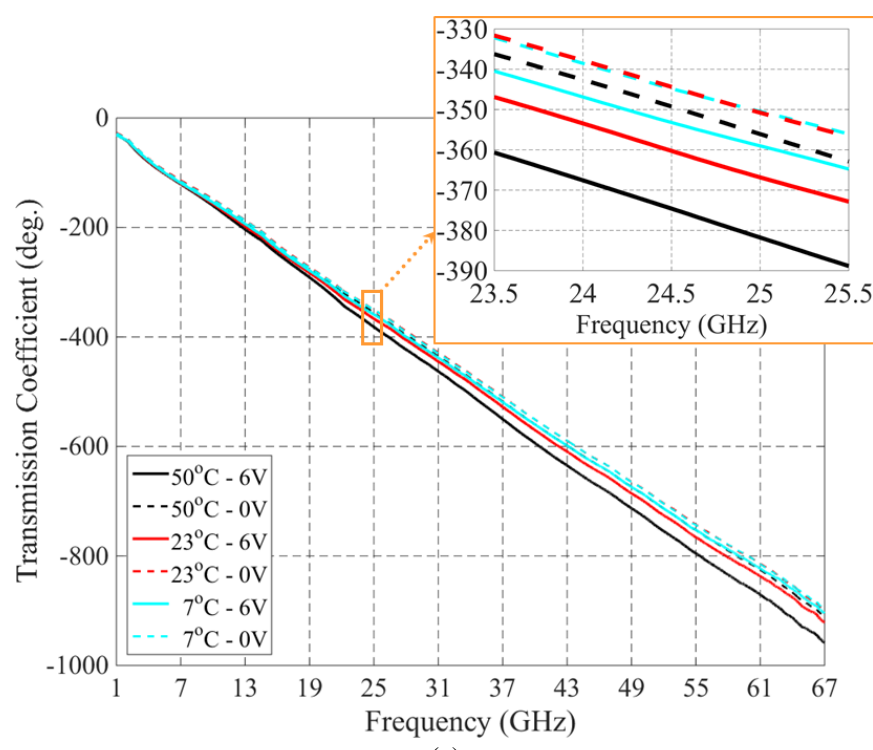

(a)

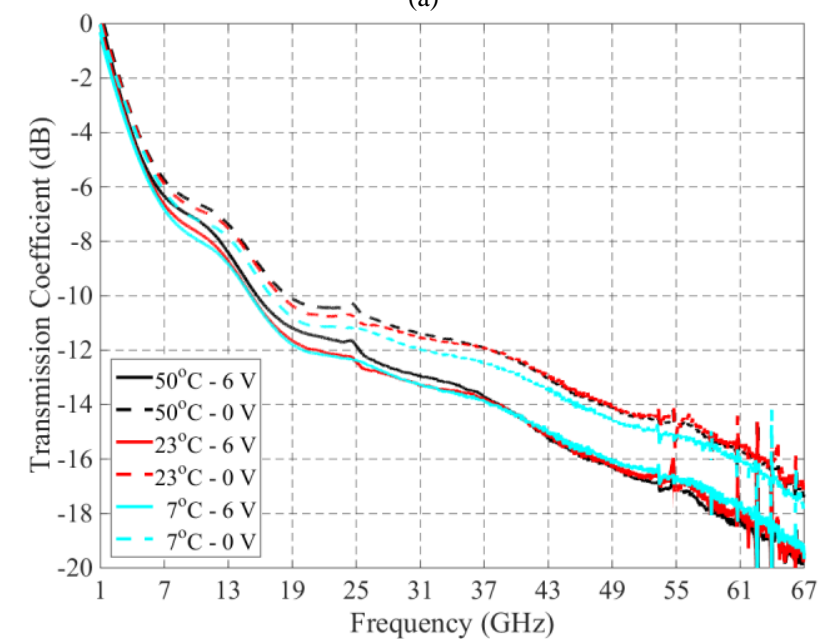

(b)

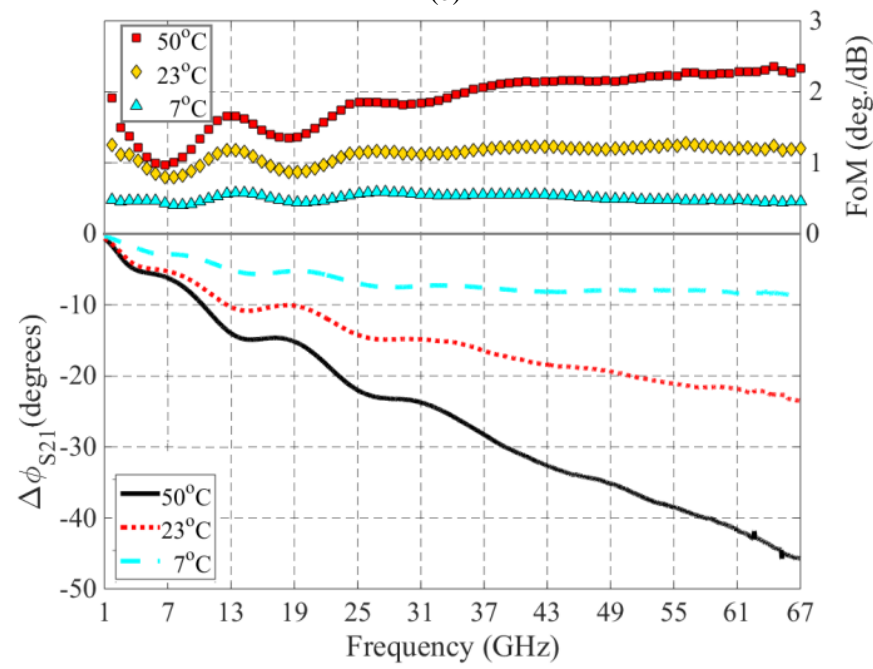

(c)

Fig. 8 Extracted parameters of the $2 \mathrm{~mm}$ long EC-based microstrip line for three measured temperatures $7{ }^{\circ} \mathrm{C}, 23^{\circ} \mathrm{C}$ and $50^{\circ} \mathrm{C}$, 'OFF' state $(0 \mathrm{~V})$ and 'ON' state (6V); (a) Phase of transmission coefficient, (b) Magnitude of transmission coefficient, (c) FoM and tunable phase shift.

operation in the frequency range of $40 \mathrm{MHz}$ to $65 \mathrm{GHz}$ [2] and second, the more sensitive frequency response of the test 
device to noise probably stems from random errors in the scattering parameter measurements. These random errors can be minimized using measurements of several transmission lines with different lengths. It is also noticed that the thickness of the thin dielectric film is much smaller than the wavelength of the highest measurement frequency so that the thin film microstrip line supports only the dominant mode [21]. Thus, these undulations are not related to high order modes which are problematic for conventional microstrip lines.

The corresponding maximum tuneable phase shift is depicted in Fig. 8 (c) across the measurement frequency range. In general, the dynamic tunability of the microstrip line is shown to increase with frequency and both the electronically reconfigurable phase range and FoM increase with temperature. For example, the $\mathrm{FoM}$ at $50^{\circ} \mathrm{C}$ is higher by a factor of 1.8 and 3.3 compared to the values obtained at $23^{\circ} \mathrm{C}$ and $7^{\circ} \mathrm{C}$, respectively.

Table II compares the phase shifting performance of the proposed EC device at different temperature conditions compared to the same LC mixtures as in Table I [6]. These results obtained for the EC material are comparable, particularly above room temperature, with the FoM data reported for single element LC materials such as K15 [6], but are lower than the values obtained for other more complex LC mixtures [7]. The main reason for this lies with high Ohmic losses associated with the conductors in TFMLs [18]. Our computations show that for a microstrip line of length $L=2$ $\mathrm{mm}$ with metal thickness and conductivity of $T=2.58 \mu \mathrm{m}, \sigma=$ $2.46 \times 10^{7} \mathrm{~S} / \mathrm{m}$, respectively, and $W / H \approx 4$, constructed with the EC material $\left(\varepsilon_{\mathrm{r}}=34.62\right.$ and $\tan \delta=0.011$, the case with $0 \mathrm{~V}$ bias at $23^{\circ} \mathrm{C}$ ), the dielectric loss is only $\alpha_{\mathrm{D}}=0.2 \mathrm{~dB}$ whereas the Ohmic loss is $\alpha_{\mathrm{C}}=10 \mathrm{~dB}$, indicating that the total loss is about $\alpha_{\mathrm{T}}=10.2 \mathrm{~dB}$ at $20 \mathrm{GHz}$ [21]. For this reason and to better illustrate the EC material performance, we have also provided in Table II (last column) the results for the $2 \mathrm{~mm}$ EC-based microstrip line, for the case when perfect conductors were used for the top microstrip line and the ground plane.

The ohmic losses depend strongly on the absolute value of the relative permittivity since this has a major impact on the distribution of the EM fields and hence the current flow along the conductors. In general, a material with a higher permittivity presents larger ohmic loss and therefore to obtain reduced losses, it is desirable to manufacture EC materials with lower dielectric constants. In light of this, the fact that ECs are composite structures makes this new class of tuneable dielectrics highly attractive for future investigation and performance improvements. More specifically, it is envisaged that the overall dielectric properties of the composite EC material (tuning ratio, relative permittivity and loss tangent) can be further engineered by adjusting the thickness and the electrical properties of the individual layers of the EC device.

\section{SATURATION LIMIT}

As common for all tunable dielectric materials, a saturation level is expected for the proposed EC material where a tuning behaviour is not achieved above a specific bias voltage. The bias voltage represents the required energy to initiate the

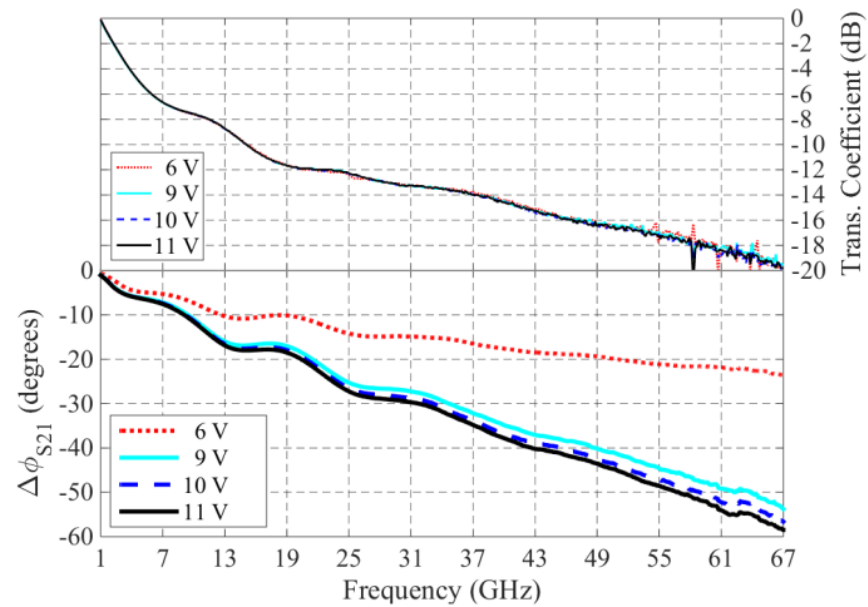

Fig. 9 Transmission coefficient amplitude and phase shift of the EC-based microstrip line in Fig. 1 (b) with $L=2 \mathrm{~mm}$ for applied bias voltages of more than $6 \mathrm{~V}$.

chemical reaction (ion/electron movements) between the electrolyte and the chromic layers of the EC material and hence it depends on the characteristics of the constituent layers such as thickness, ion and electron conductivity, etc. For the results reported in [9] and the temperature-controlled measurements in this study, an upper bias voltage limit of $6 \mathrm{~V}$ is in line with the studies in the optical frequency range [10] [11]. For example in [10], similar chromic films $\left(\mathrm{WO}_{3}\right.$ and $\mathrm{NiO})$ and electrolyte $\left(\mathrm{LiNbO}_{3}\right)$ are used with a mild difference in the thickness of layers to achieve coloration with a bias voltage of $1.5 \mathrm{~V}$.

For a better illustration of the saturation level of the EC material in the microwave frequency range and to evaluate the performance limit of the EC device in Fig. 1 (b), we have performed measurements for bias voltages higher than $6 \mathrm{~V}$; namely up to $11 \mathrm{~V}$. However, such high DC bias voltages are not recommended as long as further studies are conducted to determine the repeatability of the microwave and millimetre wave performance of EC materials with regard to power handling capability and breakdown voltage.

Another important characteristic of the EC material which requires careful attention is that although most of the coloration changes of the material takes place within a few of seconds after application of the voltage, the coloration saturation is not reached even after several minutes [11]. This should be also considered for further performance investigation of the dielectric tunability of $\mathrm{EC}$ materials at microwave frequencies.

Nevertheless, the de-embedded amplitude and phase shift of the transmission coefficient of the EC-based microstrip line is provided in Fig. 9 for bias voltages from $6 \mathrm{~V}$ to $11 \mathrm{~V}$. To perform these higher DC bias voltage measurements, DC bias voltage was gradually increased from $6 \mathrm{~V}$ to $11 \mathrm{~V}$ and the device was kept in the biased state for about 25 minutes. The voltage was applied sequentially on and off in order to prevent excessive substrate heating. As can be appreciated from Fig. 9, the small difference observed in the phase change between 10 $\mathrm{V}$ and $11 \mathrm{~V}$ indicate that the present device has reached saturation. In addition, a great improvement in the phase shift 
is also achieved which is about 2.5 times higher for a bias voltage of $11 \mathrm{~V}$ compared to $6 \mathrm{~V}$. The amplitude of the transmission coefficient remains approximately unchanged for all the reported voltages.

As suggested by this study, we may infer that the tuning saturation of the dielectric properties of the EC material may require larger bias voltages and a longer exposure times. However, this field of study requires further investigation.

\section{CONCLUSION}

In this paper we investigated the dielectric properties of an inorganic thin film EC material (WO3/LiNbO3/NiO). Numerical simulations in conjunction with $\mathrm{S}$ parameter measurements made on a fabricated CPW/microstrip/CPW test cell were used to extract the dielectric permittivity and loss tangent between $1 \mathrm{GHz}$ to $67 \mathrm{GHz}$ over the temperature range $7^{\circ} \mathrm{C}$ to $50^{\circ} \mathrm{C}$, and for $\mathrm{DC}$ bias voltages in the range 0 to $6 \mathrm{~V}$. The dynamic dielectric tunability and loss tangent over this wide frequency band are shown to be similar to the first generation of LCs (K15). At high temperatures the EC material is shown to exhibit a higher tunability albeit with a modest increase in the loss tangent, and the converse is observed below room temperature. A major drawback of LC mixtures is that it is limited in the operational temperature range in order to ensure that the specimen exists in the nematic mesophase state. However, we have demonstrated that the operation of EC is satisfactory within the range of temperatures investigated in this preliminary test campaign. $\mathrm{We}$, therefore, anticipate that thermal effects are less of a concern for EC, but further measurements below $7{ }^{\circ} \mathrm{C}$ and above $50^{\circ} \mathrm{C}$ will be required to prove this hypothesis. Favourable comparisons with $\mathrm{FE}$ have been identified, including a lower loss tangent and a requirement for a much smaller bias voltage. However to deploy EC for practical applications, it will be necessary to increase the FOM which was found to be lower than the values reported for FE and LC materials. This is largely attributed to the ohmic loss in the conductors of the TFML microstrip line. Therefore, to realise the full potential of this technology, much effort is required to overcome this limitation, for example by manufacturing lower permittivity and thicker composite EC structures in order to reduce the intensity of the electric field inside the EC based microstrip line.

\section{APPENDIX I}

The TL technique was preferred in this study over other deembedding methods such as the L-2L approach [28] which is based on two active structures, each containing an EC cell with different lengths, $\mathrm{L}$ and $2 \mathrm{~L}$. The L-2L technique, if applied to the extraction of the unknown parameters of the EC cell, would impose two restrictions. First, it would necessitate that the two active EC cells to be pre-set to the same ground reference, usually by the application of a negative bias voltage for an identical amount of time and, second, the exposure time to the bias voltages would need to be exactly the same for both structures, otherwise the extracted results will not be accurate.
The TL technique pursued in this paper does not have these limitations.

\section{ACKNOWLEDGMENT}

M. Norooziarab thanks Kieran Rainey and Dr. Dmitry Zelenchuk for performing the temperature variable measurements and DC resistance measurements. R. Kopf, T. $\mathrm{Hu}$ and A. Tate would like to thank Y. Baeyens and M. Earnshaw for their continuing support.

\section{REFERENCES}

[1] P. Queffelec et al., "Intercomparison of permittivity measurement techniques for ferroelectric thin layer", J. Appl. Phys., vol. 115, 2014.

[2] B. York, "Tunable dielectrics for RF circuits" in Multifunctional Adaptive Microwave Circuits and Systems, NC, Raleigh: Scitech, 2009.

[3] S. Bulja, D. Mirshekar-Syahkal, R. James, S. E. Day, and F. A. Fernandez, "Measurement of Dielectric Properties of Nematic Liquid Crystals at Millimeter Wavelength," in IEEE Transactions on Microwave Theory and Techniques, vol. 58, no. 12, pp. 3493-3501, Dec. 2010.

[4] M. Yazdanpanahi, S. Bulja, D. Mirshekar-Syahkal, R. James, S. E. Day, and F. A. Fernandez, "Measurement of Dielectric Constants of Nematic Liquid Crystals at mm-Wave Frequencies Using Patch Resonator," in IEEE Transactions on Instrumentation and Measurement, vol. 59, no. 12, pp. 3079-3085, Dec. 2010.

[5] R. James, F. A. Fernandez, S. E. Day, S. Bulja, and D. MirshekarSyahkal, "Accurate Modeling for Wideband Characterization of Nematic Liquid Crystals for Microwave Applications," in IEEE Transactions on Microwave Theory and Techniques, vol. 57, no. 12, pp. 3293-3297, Dec. 2009.

[6] S. Mueller et al., "Broad-band microwave characterization of liquid crystals using a temperature-controlled coaxial transmission line," in IEEE Transactions on Microwave Theory and Techniques, vol. 53, no. 6, pp. 1937-1945, June 2005.

[7] A. Penirschke et al., "Cavity perturbation method for characterization of liquid crystals up to $35 \mathrm{GHz}$, "34th European Microwave Conference, 2004, Amsterdam, The Netherlands, 2004, pp. 545-548.

[8] G. Perez-Palomino, M. Barba, JA Encinar, R. Cahill, R. Dickie, and P. Baine, "Design and Demonstration of an Electronically Beam Scanning Reflectarray at $100 \mathrm{GHz}$ Using Multi-Resonant Cells based on Liquid Crystals", Proc IEEE Antennas and Propagation, Vol. 63, No. 8, pp. 3722-3727, Aug. 2015.

[9] S. Bulja, R. Kopf, A. Tate, and T. Hu "High Frequency Dielectric Characteristics of Electrochromic, $\mathrm{WO}_{3}$ and $\mathrm{NiO}$ Films with $\mathrm{LiNbO}_{3}$ Electrolyte", Scientific Reports 6, 28839, 2016.

[10] Z. Xuping, Z. Haokang, L. Qing, and L. Hongli, "An all-solid-state inorganic electrochromic display of $\mathrm{WO}_{3}$ and $\mathrm{NiO}$ films with $\mathrm{LiNbO}_{3}$ ion conductor", IEEE Electron Device Letters, vol. 21, no. 5, pp. 215-217, May 2000.

[11] C. G. Granqvist, E. Avendaño, and A. Azens, "Electrochromic coatings and devices: survey of some recent advances, Thin Solid Films", Elsevier, vol. 442, Issues 1-2, October 2003, Pages 201-211.

[12] T. L. Rose, S. D'Antonio, M. H. Jillson, A. B. Kon, R. Suresh, and F. Wang, "A microwave shutter using conductive polymers", in Synthetic Metals 85, 1439-1440, 1997.

[13] S. Bulja and D. Mirshekar-Syahkal, "Novel Wideband Transition Between Coplanar Waveguide and Microstrip Line," in IEEE Transactions on Microwave Theory and Techniques, vol. 58, no. 7, pp. 1851-1857, July 2010.

[14] P. R. Gray, P. J. Hurst, S. H. Lewis, and R. G. Meyer, "Analysis and Design of Analog Integrated Circuits", $5^{\text {th }}$ ed. John Wiley \& Sons Inc, 2009.

[15] C. G. Granquist, "Handbook of inorganic electrochromic materials", Elsevier, 1995.

[16] R. J. Mortimer, "Electrochromic Material" in Annual Review Materials Research. 41, pp. 241-268, 2011.

[17] J. C. Chou et al., "A Study on Electrochemical and Optical Characteristics of WO Electrochromic Thin Film Prepared by Different Constant Potentials and Deposition Time", in Journal of Display Technology, vol. 12. No. 2, pp. 109-114, February 2016. 
[18] M. Norooziarab, S. Bulja, R. Cahill, R. Kopf and, A. Tate, "Complex dielectric permittivity extraction based on multilayer thin film microstrip lines," in IET Microwaves, Antennas \& Propagation, vol. 11, no. 7, pp. 955-960, 622017.

[19] A. Koul, M. Y. Koledintseva, S. Hinaga, and J. L. Drewniak, "Differential Extrapolation Method for Separating Dielectric and Rough Conductor Losses in Printed Circuit Boards," in IEEE Transactions on Electromagnetic Compatibility, vol. 54, no. 2, pp. 421-433, April 2012.

[20] D. M. Pozar, "Microwave Engineering", 4th ed. John Wiley \& Sons Inc. 1996.

[21] G. A. Kouzaev, M. J. Deen, and N. K. Nikolova, "A parallel-plate waveguide model of lossy microstrip lines," in IEEE Microwave and Wireless Components Letters, vol. 15, no. 1, pp. 27-29, Jan. 2005.

[22] M. D. Janezic and J. A. Jargon, "Complex permittivity determination from propagation constant measurements," in IEEE Microwave and Guided Wave Letters, vol. 9, no. 2, pp. 76-78, Feb 1999.

[23] Ge Song, S. Follonier, A. Knoesen, and R. D. Miller, "Characterization of thin-film low-dielectric constant materials in the microwave range using on-wafer parallel-plate transmission lines," in IEEE Microwave and Guided Wave Letters, vol. 10, no. 5, pp. 183-185, May 2000.

[24] S. Holten and H. Kliem, J. Appl. Phys. 90, 1941, 2001.

[25] C. W. Byeon and C. S. Park, "A Low-Loss Compact 60-GHz Phase Shifter in 65-nm CMOS," in IEEE Microwave and Wireless Components Letters, vol. 27, no. 7, pp. 663-665, July 2017.

[26] D. Mitra, P. Roy, and D. Dawn, "A variable gain CMOS phase shifter for phased array antenna applications" in Microwave and Optical Technology Letters, 59: 324-328, Dec. 2016.

[27] R. Dickie et al., "Electrical characterization of liquid crystals at millimeter wavelengths using frequency selective surfaces," in Electronics Letters, vol. 48, no. 11, pp. 611-612, May 242012.

[28] T. Hirano et al., "Accuracy investigation of de-embedding techniques based on electromagnetic simulation for on-wafer RF measurements," INTECH Open Access Publisher, 2012.

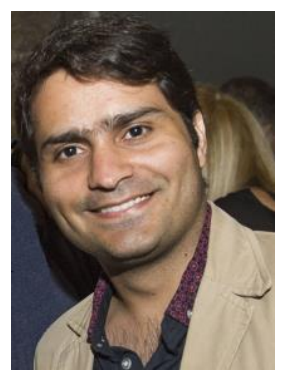

Majid Norooziarab received the B.Sc. and the M.Sc. degrees in electrical engineering from Shahid Beheshti University, Tehran, Iran, and Tarbiat Modares University, Tehran, Iran, in 2009 and 2012, respectively. He is currently pursuing the Ph.D. degree in electrical engineering as an Early Stage Marie Curie Researcher at Queen's University Belfast, Belfast, U.K. From 2015 to 2017, he was with Nokia Bell Laboratories, Dublin, Ireland, as a research intern. His research interests include RF characterization of materials and tunable materials for reconfigurable microwave and millimeter wave devices and antennas.

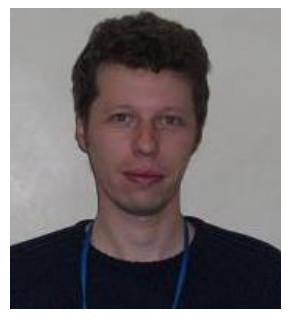

Senad Bulja (M'07-SM'12) received the B.Eng. (Hons.) and Ph.D. degrees from the University of Essex, Colchester, U.K., in 2002 and 2007, respectively.

From 2007 to 2010, he was a Senior Research Officer with the School of Computer Science and Electronic Engineering, University of Essex, where he was involved in the characterization of liquid crystals at microwave and millimeter-wave frequencies, and the development of liquid-crystal-based millimeter-wave devices. In 2010, he joined Nokia Bell Laboratories, Dublin, Ireland, where he is currently a Member of Technical Staff. He has authored or coauthored over 40 papers in international journals and conference proceedings and holds nearly 40 patents. His current research interests include variable microwave devices, microwave amplifier linearization techniques, memory effects description in RF transistors, characterization of liquid crystals, new bulk tunable media at microwave and millimeter-wave frequencies, and microwave filters.

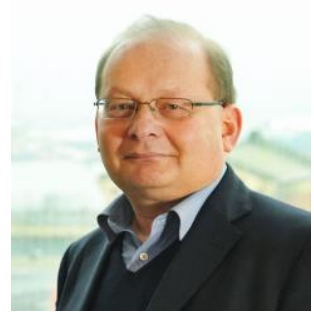

Robert Cahill (M'10-SM'11) received a BSc honours degree in Physics from the University of Aston in Birmingham in 1979 and a $\mathrm{PhD}$ degree in microwave electronics from the University of Kent at Canterbury in 1982. He joined Queen's University Belfast (QUB) in 1999 after a 17 year career working in the UK space and defense industry, where he worked on antenna and passive microwave device technology projects. During this time he pioneered methods for predicting the performance of antennas on complex scattering surfaces such as satellites and has developed techniques for analyzing and fabricating $\mathrm{mm}$ and sub- $\mathrm{mm}$ wave quasi-optical dichroic filters. Recently he has established a $100-700 \mathrm{GHz}$ quasioptical S parameter measurement facility at QUB. He has exploited the results of numerous research projects, sponsored by the European Space Agency, EADS Astrium Space Ltd, the British National Space Agency, the Centre for Earth Observation Instrumentation (CEOI) and the UK Meteorological Office, to develop quasi-optical demultiplexers for atmospheric sounding radiometers in the range 89$500 \mathrm{GHz}$. These include AMSU-B, AMAS, MARSCHALS and the ESA $500 \mathrm{GHz}$ demonstrator. Dr Cahill's recent interests also include the characterization of liquid crystal materials at microwave and $\mathrm{mm}$ wavelengths, and strategies for broad banding and creating active reflectarray antennas. He has (co) - authored over 130 publications and holds 4 international patents.

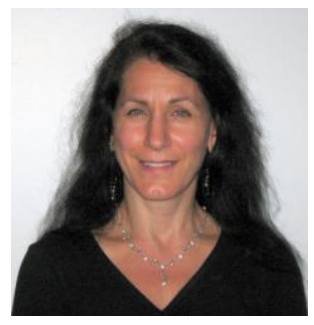

Rose Kopf is a Member of the Technical Staff in the Emerging Materials, Components and Device Research group at NOKIA Bell Labs in Murray Hill, New Jersey, USA. She received a B.S. degree in Chemistry from Northeastern University, Boston, MA, and M.S. and Ph.D. degrees in Materials Science and Engineering from Stevens Institute of Technology in Hoboken, NJ. Prior to joining Bell Labs, Dr. Kopf was an analytical chemist at Arthur D. Little, Inc., Cambridge, MA. During her tenure at NOKIA, she was involved in MBE growth of GaAs/AlGaAs and InGaAs/InAlAs heterojunctions for optical and electronic devices and circuits, and later in InP process development and integration for HBT high-speed circuits and optoelectronic integrated circuits. More recently, she has been involved in micro/nano device fabrication for hybrid integration. She has over 200 publications in the semiconductor field and holds 20 patents.

TING-CHEN HU is a Member of Technical Staff in the Emerging Materials, Components, and Devices Research group at NOKIA Bell Labs in Murray Hill, New Jersey, USA. He received a B.S. degree in Physics from National Cheng Kung University, Taiwan, a M.S. degree in Material Sciences and Engineering from National Chiao Tung University, Taiwan, and a Ph.D. degree in Electrical Engineering from University of California at Los Angeles. At Nokia, Dr. Hu has been working on the development of InP/InGaAs-based HBTs, high-speed photodetectors, and optical modulators and providing e-beam lithography process solutions for nano-meter electronic and optical device fabrication. His current research interests include the design and fabrication of micro/nano devices for hybrid integration and 3D patterning.

ALARIC TATE is a Member of Technical Staff in the Emerging Materials, Components, and Devices Research group at NOKIA Bell 
Labs in Murray Hill, New Jersey, USA. He received the A.B. degree in Materials Engineering from Brown University, Providence, Rhode Island, and an M.E. degree in Interdisciplinary Engineering from Stevens Institute of Technology, Hoboken, New Jersey. Past efforts have included process engineering in the development of advanced packages for Si-based multi-chip modules (MCMs), the fabrication of InP-based distributed feedback (DFB) lasers, and providing stepper lithography-based process solutions in the fabrication of InP/InGaAsbased HBTs and photodetectors. More recently, he has been involved in micro/nano device fabrication for hybrid integration. $\mathrm{He}$ is currently serving as chair of the American Society of Mechanical Engineers (ASME)-Mid Jersey Chapter. 